\section{ACONDICIONAMIENTO DE LA DELEGACION DE ZARAGOZA DEL COLEGIO OFICIAL DE ARQUITECTOS DE ARAGON Y LA RIOJA ZARAGOZA/ESPAÑA}

\author{
Isabel García Lorza y \\ Manuel Fernández Ramírez, \\ Arquitectos
}

$128-2$

\section{SINOPSIS}

El acondicionamiento de este edificio alcanzó a todas aquellas obras necesarias para su adecuación a las nuevas funciones de organización colegial, así como a los refuerzos estructurales y de renovación de cubiertas que su estado exigió realizar.

Los elementos arquitectónicos de gran importancia histórico-artística (patio central, artesonado, etc.) han sido respetados y revalorizados en todas sus posibilidades, intentando recuperarlos a su verdadero estado primitivo.

\section{Evolución histórica}

El edificio, situado en la Plaza de Santa Cruz esquina a la Calle de San Voto, era el resultado de una serie de reformas y ampliaciones sufridas a lo largo de los años para adaptarlo a las funciones que en cada momento necesitaba desarrollar, una vez perdido el carácter primario para el que fue construido. Sin embargo, debido a la clara organización y distribución primitivas en planta, conserva todavia en gran medida la tipología clásica de las casas-palacio, construidas en Zaragoza durante su época renacentista.

El conjunto antiguo - fachada a la Calle de San Voto- consta de cuatro plantas: baja, noble, ático y sótano. Al igual que todas estas casas-palacio, se desarrolla alrededor de un patio interior, como núcleo del edificio, al que se accede desde el zaguán de la entrada de la Calle de San Voto. Tanto esta entrada, que desde el exterior conduce al patio, como la escalera, que partiendo de él en planta baja lleva al patio en las sucesivas plantas, como la disposición de las estancias alrededor del mismo, contribuyen a darle este carácter nuclear.
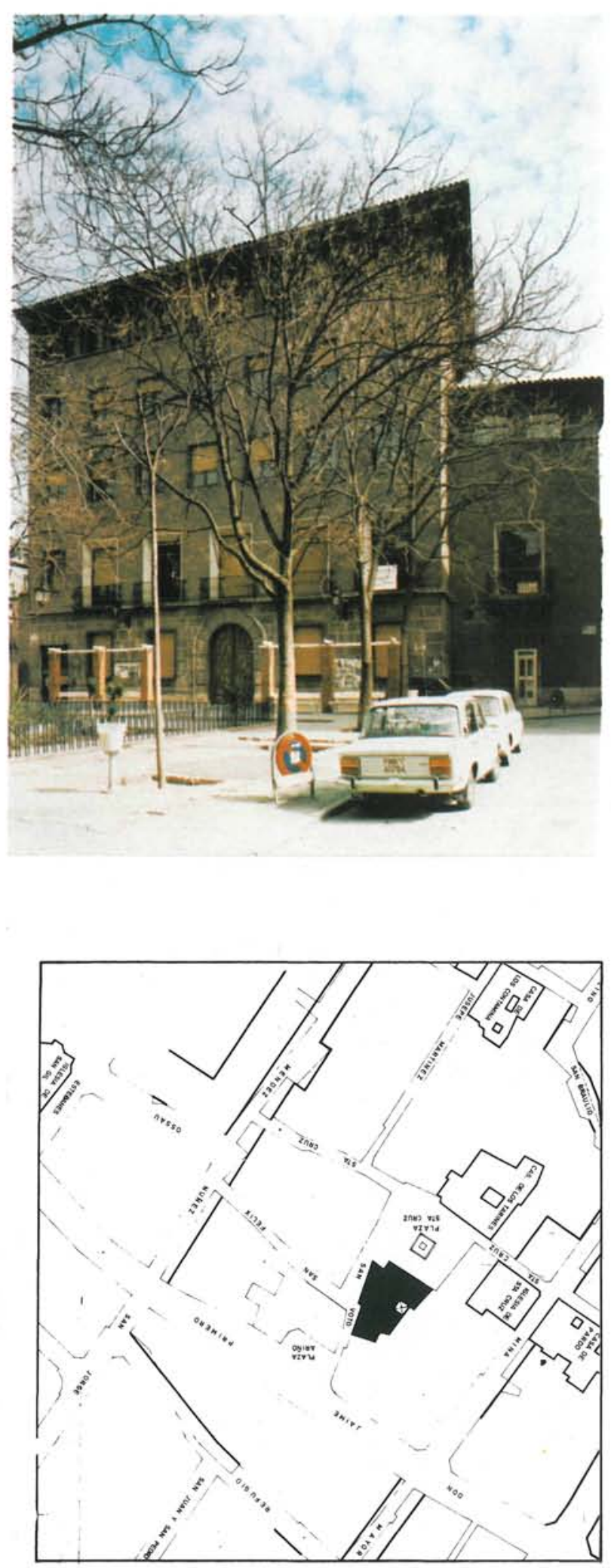

plano de situación 

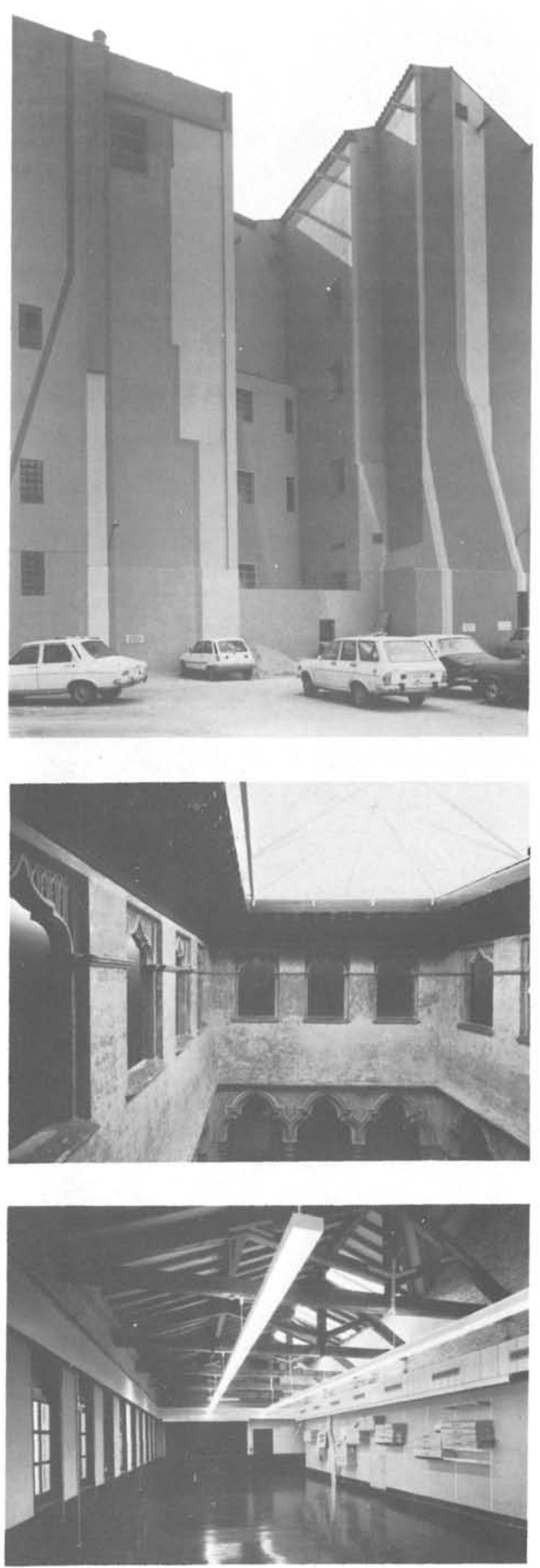

El patio, en planta baja, está formado por una estructura porticada exenta, a base de puentes de madera y cuatro columnas, realizándose la articulación entre éstas por medio de ménsulas. Estas columnas, debido a las sobrecargas a que fue sometido el edificio en su última fase de transformación, quedaron totalmente embebidas en un zunchado de hormigón de pésima calidad, atacado por ser de piedra de yeso su núcleo interior. En la planta noble, se encuentran arquillos de relleno entre los elementos estructurales, que no tienen una función sustentante sino ornamental, creando una galeria que consta de unas columnas y pequeños arcos de aspecto gótico tardio. En la planta ático, la galeria se hace más ciega que en la planta noble, a base de pequeños ventanales de yeso tallado con labores de gótico tardio, intercalándose en un muro ciego.

Alrededor de este patio se desarrollaban las distintas dependencias, quedando abierto al exterior cenitalmente.

El conjunto de zaguán, patio, escalera y dependencias constituye un todo ordenado y muy relacionado entre si.

El sótano se desarrolla alrededor de un espacio central, coincidente con el patio, siguiendo la misma ordenación del edificio. Estructuralmente responde a un sistema de muros de ladrillo y bovedas a panderete y sardinel.

El conjunto de las fachadas se encuentra dividido en tres cuerpos horizontales correspondientes a las tres plantas interiores. El ático está realizado como una galería corrida de arcos de medio punto, no abocinados, y elementos porticados dejando, como es usual en estos edificios, el gran alero y la gran masa del tejado sobre esta franja horizontal tan calada y en contraste con los grandes planos macizos de las plantas noble y baja.

En el edificio existen dos zonas claramente diferenciadas: la parte antigua, que se mantiene esencialmente como se ha descrito, y la zona de la Plaza de la Santa Cruz, construida durante los años 1942 a 1946.

Ambas zonas se encuentran articuladas por la escalera principal que se mantiene en su disposición primitiva, y a la que se hicieron pequeñas reformas para adaptarla al nuevo conjunto.

En este último período también se añadieron dos nuevos niveles sobre la planta ático del edificio antiguo, de pésima calidad arquitectónica, que al sobrecargar la estructura provocaron la fisuración de una de las columnas del patio, obligando al zunchado de todas ellas y disminuyendo considerablemente la calidad del conjunto.

El elemento más degradado, en cuanto a su funcionamiento y concepción primitivas, ha sido la 
escalera, ya que al cegarse su comunicación con el patio para abocarla a la nueva entrada de la Plaza de la Santa Cruz, crea una circulación contradictoria en las plantas superiores, y el patio pierde el carácter de núcleo central del edificio, careciendo la entrada principal de una conexión directa con él.

De igual manera, la entrada antigua al edificio de la Calle de San Voto, quedó completamente desvirtuada al situarse en ella tortuosamente la escalerilla que conduce al coro de la capilla.

Estructuralmente el edificio se encontraba en un estado bastante aceptable, teniendo en cuenta su antigüedad, por lo que el acondicionamiento actual, en este aspecto, se proponia resolver problemas localizados que pudieran afectar a la estructura en el futuro.

\section{Razonamiento y descripción del proyecto}

Las obras de la remodelación del edificio se limitan única y exclusivamente a su acondicionamiento con un sentido claro, por parte del Colegio Oficial de Arquitectos, de restaurar y conservar aquellos elementos histórico-artísticos salvándolos de un progresivo deterioro, al mismo tiempo que se les dotaba de unas funciones y aprovechamiento que, en gran medida, repercutirán en la ciudad.

Se ha partido, en base a un programa de necesidades, del nuevo esquema de organización y funcionamiento colegial. Este programa determina una serie de relaciones entre los distintos departamentos y su proyección exterior - pública- o interior - hacia los colegiados-.

Lógicamente, el esquema de organización de funciones dentro del edificio no es rigido; la gran cantidad de espacio disponible y la imprevisión del desarrollo futuro del Colegio, obliga a dotar a la mayoria de los espacios de una flexibilidad que pueda permitir su revisión en años sucesivos.

Las funciones colegiales se agrupan en las distintas plantas del edificio según el siguiente planteamiento:

La planta baja, con un carácter marcadamente público, comunica, a través del patio interior, el acceso de la plaza de la Santa Cruz y la Calle de San Voto. Para lograr una mayor claridad en esta circulación se restituye la escalera principal del edificio a su trazado primitivo, y se elimina la escalerilla de acceso al actual coro de la capilla.

Desde esta planta baja se articulan los espacios destinados a información pública, salón de reuniones y salas de exposiciones del sótano. La acce-

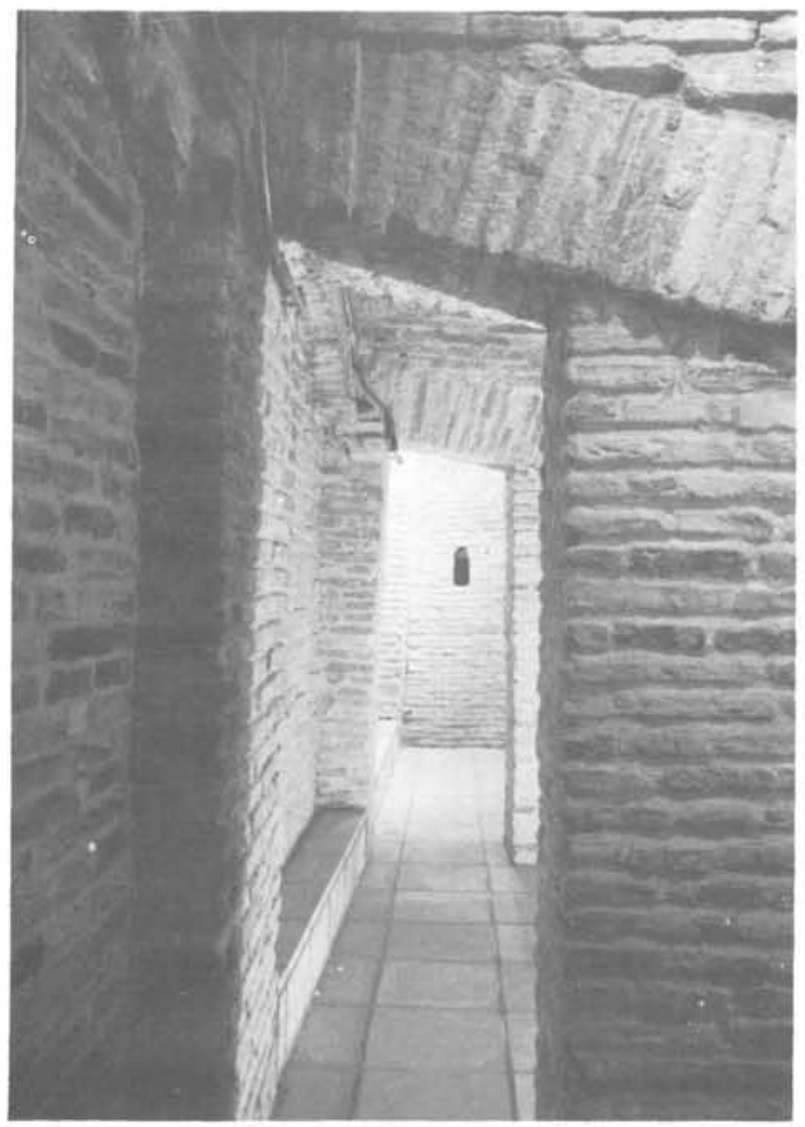

acondicionamiento de sótanos

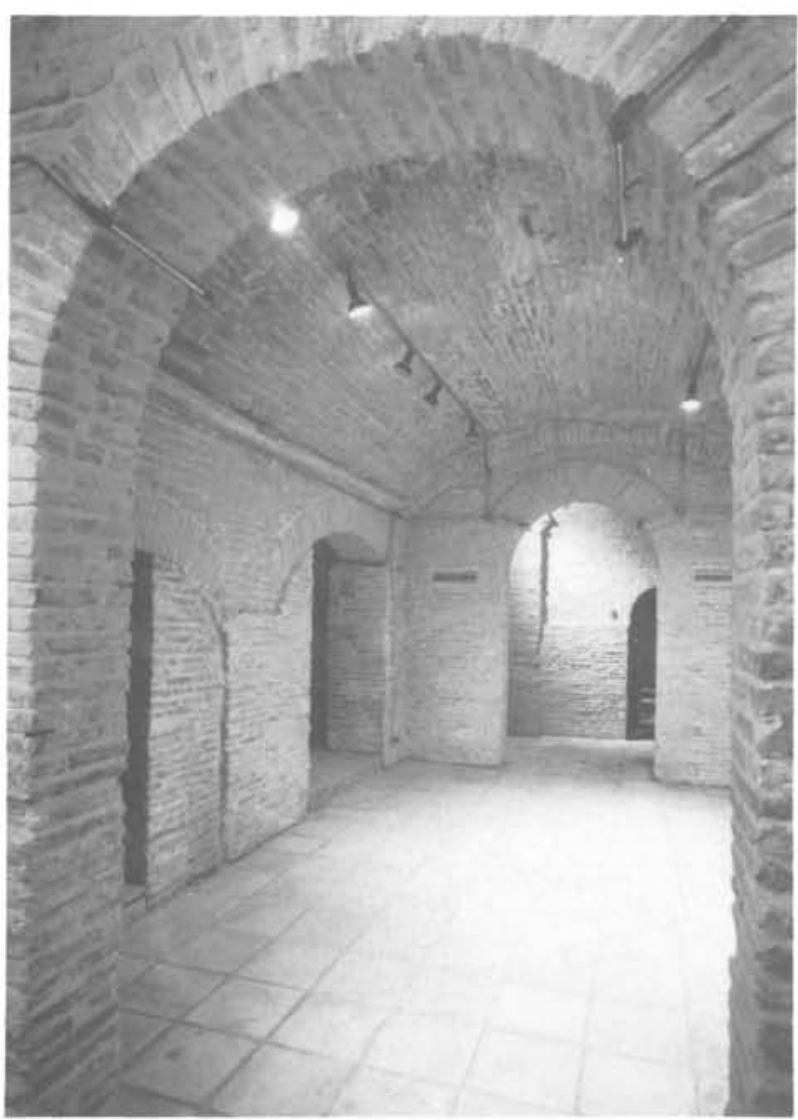



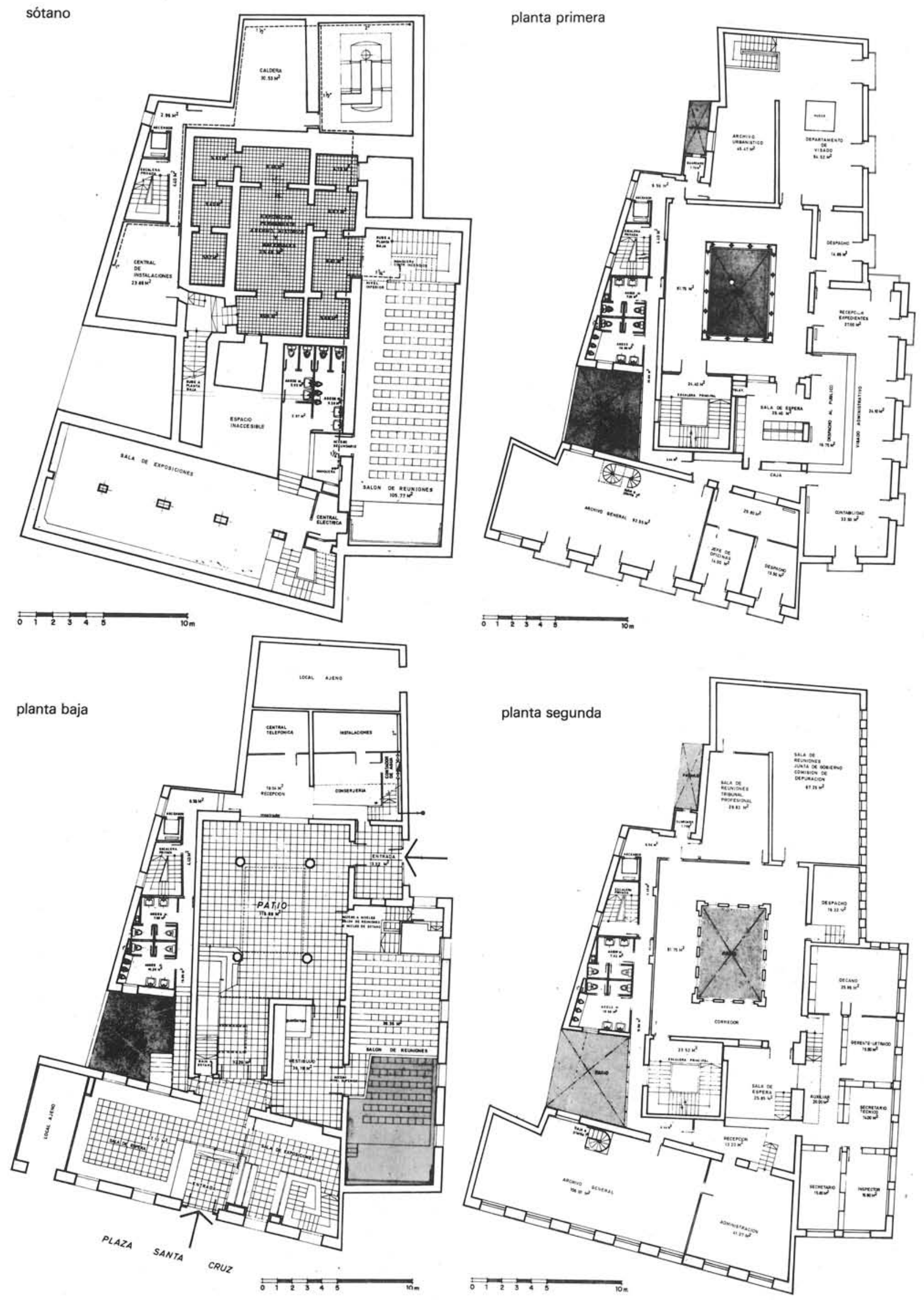

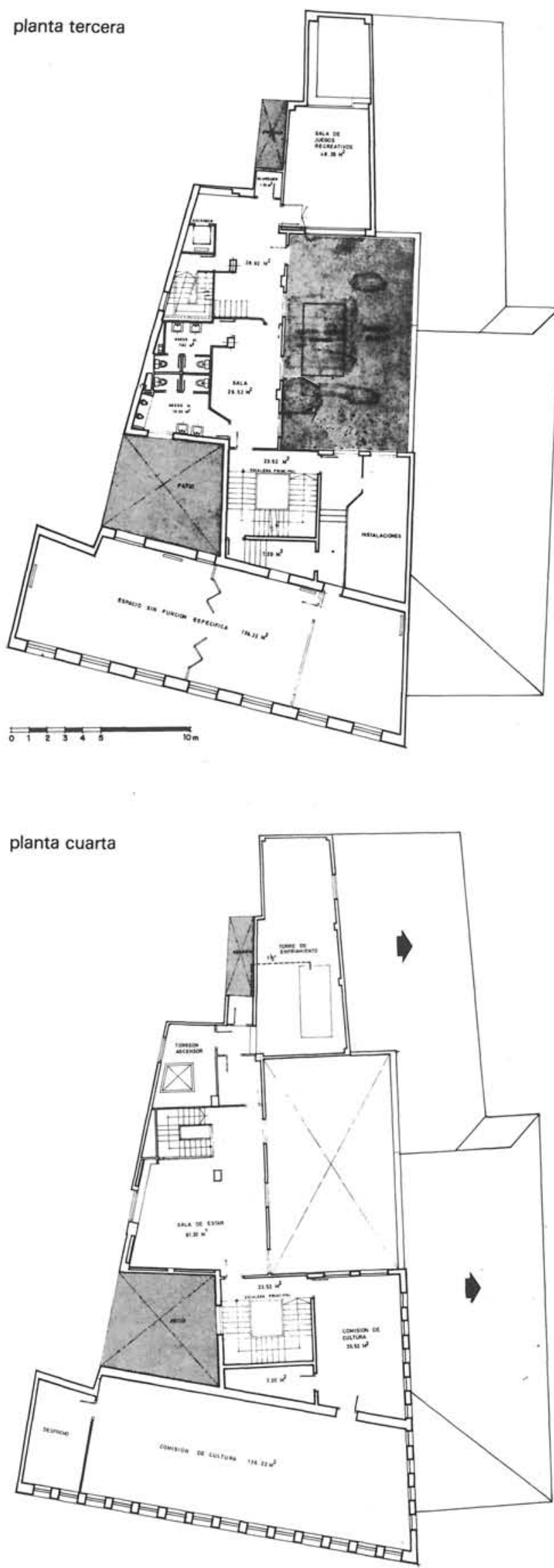

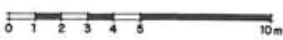

sibilidad a éste se ha conseguido mediante la incorporación de dos escaleras secundarias que, al tiempo que cumplen dicha función, sirven para comunicación directa con los niveles del salón de reuniones. De esta forma el sótano queda lo suficientemente accesible como para revalorizar su núcleo central y aprovecharlo en su totalidad.

El salón de reuniones, como pieza, en cierto modo fundamental del edificio, ha surgido de la unión del volumen destinado a capilla en planta baja con el volumen inferior del sótano. Para ello se ha eliminado el forjado intermedio, en malas condiciones, transmitiéndose las cargas directamente al terreno con una estructura totalmente independiente. De esta forma ha resultado un local con capacidad para unas 250 personas.

Las circulaciones superiores se desarrollan a través de la escalera principal con carácter público, y por medio de una escalera secundaria y un ascensor situados en la medianera del edificio con carácter privado.

En planta baja se dispone también una oficina de información pública que, articulando los niveles de la entreplanta y primera, comunica directamente con las dependencias superiores.

La planta primera se destina especificamente a las funciones de la Delegación de Zaragoza. La sala de despacho al público está integrada en la zona noble del primitivo edificio, incorporando a la vision en su totalidad el valioso artesonado de madera, en perfectas condiciones de conservación.

Existen dos circulaciones a nivel de planta: la primera alrededor del patio y con un carácter público, accediendo fácilmente a cualquier dependencia. La segunda, concéntrica con la anterior, establece un recorrido de servicio a través de todos los departamentos e incluso del patio lateral por medio de una pasarela volada.

El espacio destinado a archivo general se articula con otro análogo situado en la planta superior, y puede ser utilizado tanto por la Delegación como por el Colegio.

En planta segunda se disponen las dependencias colegiales. Con fácil acceso desde la sala de espera, se desarrollan los despachos de los diferentes servicios colegiales y la zona destinada a administración.

También existe una doble circulación horizontal, análoga a la de la planta inferior.

La planta tercera no tiene una función especifica. Se reserva para previsiones futuras. Desde ella se accede a la terraza situada encima del patio central del edificio. 

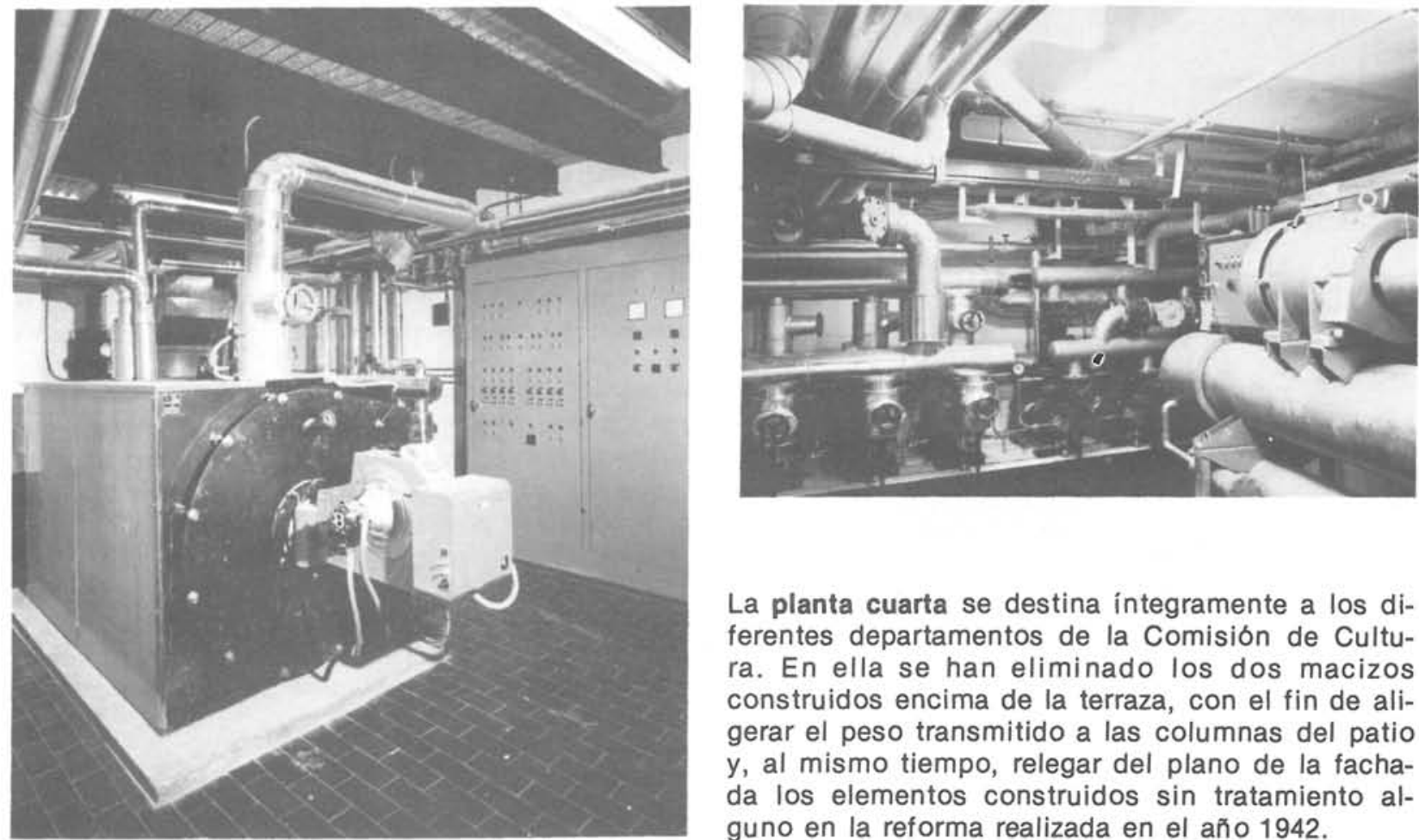

La planta cuarta se destina integramente a los diferentes departamentos de la Comisión de Cultura. En ella se han eliminado los dos macizos construidos encima de la terraza, con el fin de aligerar el peso transmitido a las columnas del patio $y$, al mismo tiempo, relegar del plano de la fachada los elementos construidos sin tratamiento alguno en la reforma realizada en el año 1942.

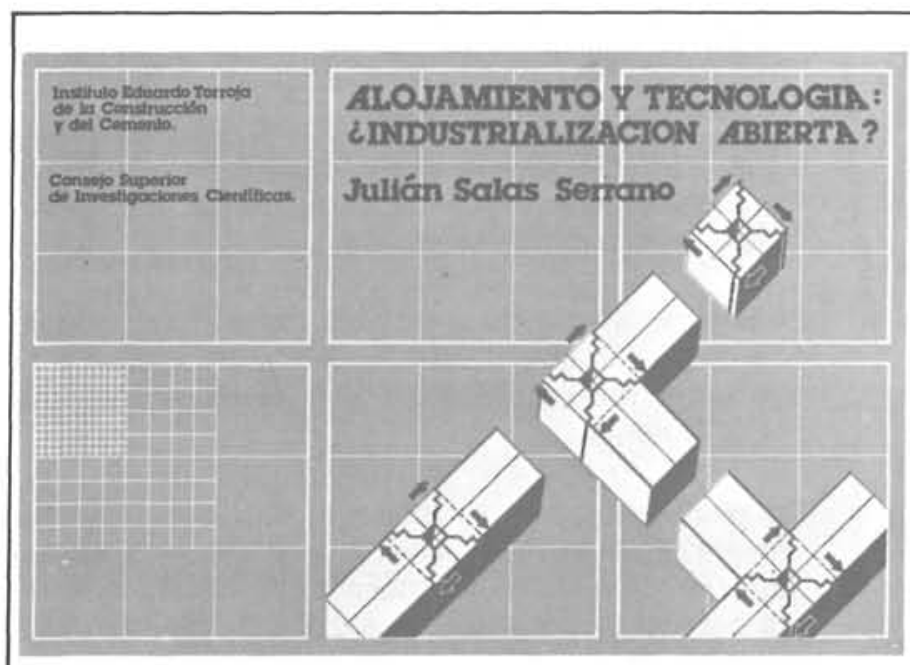

\section{ALOJAMIENTO Y TECNOLOGIA: ¿INDUSTRIALIZACION ABIERTA?}

JULIAN SALAS, ING. IND. (I.E.T.c.c.)

Un volumen de 160 páginas, 109 figuras y 16 tablas. Tamaño $240 \times 168 \mathrm{~mm}$. Encuadernado en rústica. Precios: España, 1.200 ptas; extranjero, 24 \$ USA.

\section{SUMARIO:}

Prólogo Prof. G. Ciribini.

\section{Introducción}

Capítulo 1.-La industrialización en las proclamas y manifiestos de arquitectura.

Capítulo 2.-¿Réquiem por la construcción industrializada?

Capítulo 3.-Algunos conceptos básicos.

Capítulo 4.- ¿Proyecto tradicional, construcción industrializada?

Capitulo 5. - Componentes.

Capítulo 6. - La coordinación dimensional hoy.

Capítulo 7.-Flexibilidad, intercambiabilidad y catálogos.

Capítulo 8.-Industrialización, normativa y calidad.

Capítulo 9.-Reflexiones finales.

publicación del

INSTITUTO EDUARDO TORROJA 